http://jmscr.igmpublication.org/home/ ISSN (e)-2347-176x ISSN (p) 2455-0450 crossref DOI: https://dx.doi.org/10.18535/jmscr/v8i8.19

\title{
Morphometric Study of Proximal End of Humerus in North Indian Population
}

\author{
Authors \\ Shirin Jahan, Rahul Srivastava* \\ Department of Anatomy, Rama Medical College, Kanpur, Uttar Pradesh \\ *Corresponding Author \\ Rahul Srivastava \\ Department of Anatomy, Rama Medical College, Kanpur, Uttar Pradesh, India
}

\begin{abstract}
Background: Many orthopaedic treatments need a proper measurement of bone and morphometric analysis of bone also very useful in forensic anthropology and many more fields. Morphometric studied data also help in reconstruction of bone and a proper surgical planning.

Objectives: To determine the dimension of proximal end of humerus

Material and Methods: Thirty humerus were taken without know sex. HL (Humerus length): The distance between the highest point of the humeral head and the lowest point of the trochlea. TDHH (Transverse diameter of humeral head): The diameter of the humerus head in the antero-posterior direction. VDHH (Vertical diameter of humeral head): The diameter of the bone in the lateral-medial direction. HH GT (Highest Point of Humeral Head and Greater Tubercle): The distance between the highest point of the humeral head and the highest point of the greater tubercle.

Results: The mean length of humerus on left side is 290.2 and 291.02 on right side. The mean of the transverse diameter of humeral head is $39.53 \mathrm{~mm}$ and left side is $36.99 \mathrm{~m}$. The mean vertical diameter of humeral head with respect to lateral-medial direction on right side is $41.63 \mathrm{~mm}$ and on the left side is $38.89 \mathrm{~mm}$. The mean of highest point of humeral head and greater tubercle on right side is $7.24 \mathrm{~mm}$ and on the left side is $6.25 \mathrm{~mm}$

Keywords: Head of humerus, Humerus, Humerus proximal end.
\end{abstract}

\section{Introduction}

The humerus is longest and largest bone of the upper limb. It has expanded ends and a shaft. The upper end comprises of rounded head, the proximal and medial part of the upper end of the bone and forms an enarthrodial articulation with the gleniod cavity of the scapula. The lesser tubercle projects from the front of the shaft close to the head and is limited on its lateral side by a well marked bicipital groove. The distal end loosely termed condylar is adapted to the forearm bones at the elbow joint. The capsular ligament of the elbow joint is attached anteriorly to the upper limits of the radial and coronoid fossae so that both these bony depressions are intracapsular and therefore lined with synovial membrane. The 
lesser tubercle projects from the front of the shaft close to the head and is limited on its lateral side by a well- marked bicipital groove.

The proximal segment of the humerus consists of the head, anatomical neck and greater and lesser tubercles. The head of the humerus forms rather less than half a spheroid. Its smooth articular surface is covered with hyaline cartilages, which is thicker centrally. When the arm is at rest by the side it is directed medially, backwards and upwards to articulate with glenoid cavity of scapula. ${ }^{1}$ the morphometric segments of humerus very help for anthropologist, anatomists and in forensic for identification of skeleton. ${ }^{2}$ Clinically the proximal and distal humerus fracture are commonly in elderly people. ${ }^{3}$ Some common facture are Avulsion fracture in greater tubercle, sometime dislocation also cause facture in proximal end of humerus. ${ }^{4}$

\section{Material and Methods}

Study Population: The study was carried out on thirty dry adult humerus with unknown gender collected from Department of Anatomy, Rama Medical College Manadhana Kanpur over a period of six-month July 2018 to December 2018.

\section{Methods}

The different parameters of each humerus were measured by with the help of Digital Vernier calipers.

Measurements to be determined are as follows:

1. HL (Humerus length): The distance between the highest point of the humeral head and the lowest point of the trochlea.
2. TDHH (Transverse diameter of humeral head): The diameter of the humerus head in the antero-posterior direction.

3. VDHH (Vertical diameter of humeral head): The diameter of the bone in the lateral-medial direction.

4. HH GT (Highest Point of Humeral Head and Greater Tubercle): The distance between the highest point of the humeral head and the highest point of the greater tubercle.

Inclusion Criteria: Complete unbreakable Humerus.

Exclusion Criteria: Broken Humerus.

Statistical Analysis: Statistical analysis was performed by using computer-based software, Statistical Package for Social Science (SPSS). Mean values of parameters were compared to determine.

\section{Result}

In the present study, the mean length of humerus on left side is 290.2 and 291.02 on right side. Show in Table No. 1. The mean of the transverse diameter of humeral head is $39.53 \mathrm{~mm}$ and left side is $36.99 \mathrm{~mm}$ show in the table No 2. The mean vertical diameter of humeral head with respect to lateral-medial direction (VDHH) on right side is $41.63 \mathrm{~mm}$ and on the left side is $38.89 \mathrm{~mm}$ show in table no 3 . The mean of highest point of humeral head and greater tubercle on right side is $7.24 \mathrm{~mm}$ and on the left side is $6.25 \mathrm{~mm}$ shown in Table No.4.

Table 1 Distribution of mean height of humerus

\begin{tabular}{|c|c|c|c|c|c|}
\hline \multicolumn{3}{|c|}{ Left side } & \multicolumn{3}{c|}{ Right side } \\
\hline Mean & $\begin{array}{c}\text { Std. } \\
\text { Deviation }\end{array}$ & $\begin{array}{c}\text { Std. Error } \\
\text { Mean }\end{array}$ & Mean & Std. Deviation & $\begin{array}{c}\text { Std. Error } \\
\text { Mean }\end{array}$ \\
\hline $290.2 \mathrm{~mm}$ & $27.8 \mathrm{~mm}$ & $71 \mathrm{~mm}$ & $291.2 \mathrm{~mm}$ & $28.7 \mathrm{~mm}$ & $74 \mathrm{~mm}$ \\
\hline
\end{tabular}




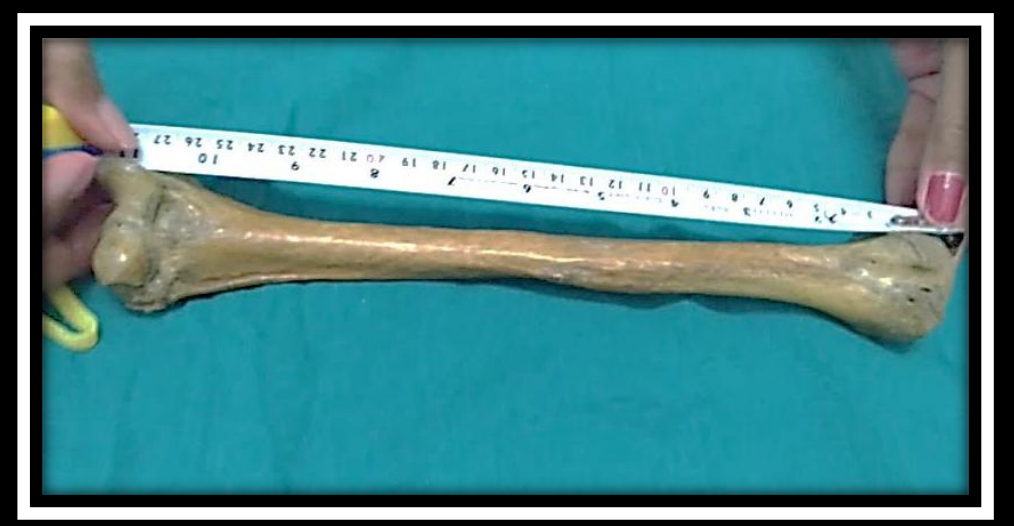

Fig. 1 Showing measurement of length humerus

Table 2 Mean value of transverse diameter humeral head

\begin{tabular}{|c|c|c|c|c|c|}
\hline \multicolumn{3}{|c|}{ LEFT TDHH } & \multicolumn{3}{c|}{ RIGHT TDHH } \\
\hline Mean & Std. Deviation & $\begin{array}{c}\text { Std. Error } \\
\text { Mean }\end{array}$ & Mean & Std. Deviation & $\begin{array}{c}\text { Std. Error } \\
\text { Mean }\end{array}$ \\
\hline $36.99 \mathrm{~mm}$ & $3.11 \mathrm{~mm}$ & $0.84 \mathrm{~mm}$ & $39.53 \mathrm{~mm}$ & $4.83 \mathrm{~mm}$ & $1.24 \mathrm{~mm}$ \\
\hline
\end{tabular}

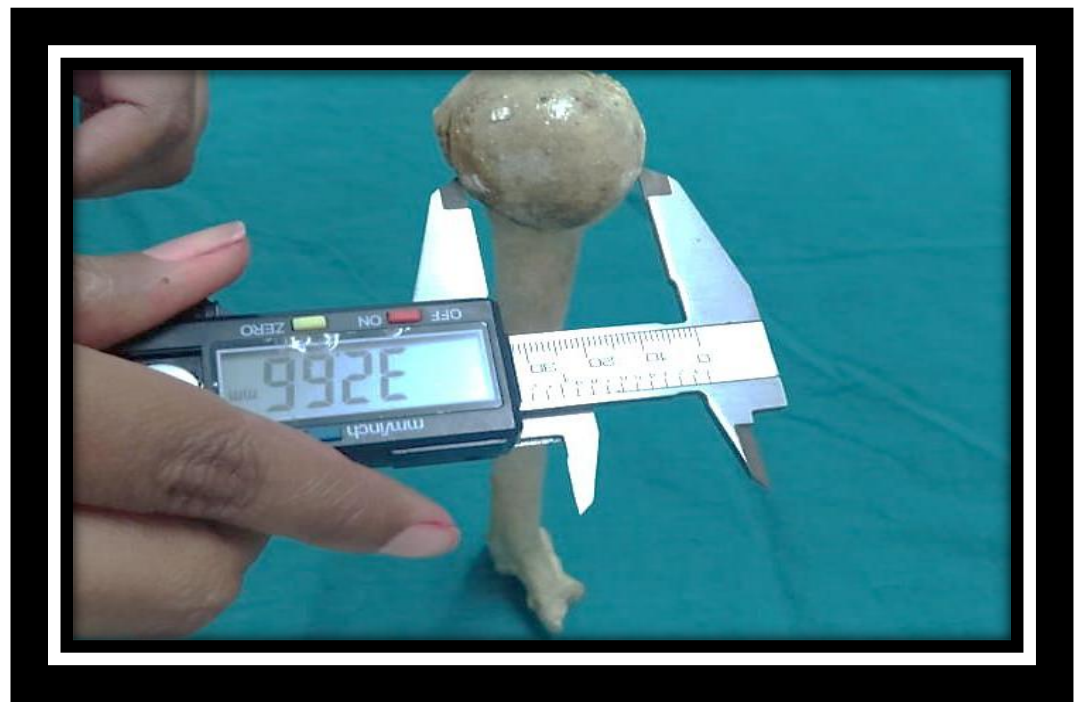

Fig. 2 showing measurement of trans verse diameter humeral head

Table 3 Distribution of mean vertical diameter of humeral head

\begin{tabular}{|r|r|r|r|r|r|}
\hline & LEFT VDHH & & \multicolumn{2}{r|}{ RIGHT VDHH } \\
\hline Mean & $\begin{array}{r}\text { Std. } \\
\text { Deviation }\end{array}$ & $\begin{array}{r}\text { Std. Error } \\
\text { Mean }\end{array}$ & Mean & $\begin{array}{r}\text { Std. } \\
\text { Deviation }\end{array}$ & $\begin{array}{r}\text { Std. Error } \\
\text { Mean }\end{array}$ \\
\hline $38.89 \mathrm{~mm}$ & $3.71 \mathrm{~mm}$ & $0.95 \mathrm{~mm}$ & $41.63 \mathrm{~mm}$ & $1.55 \mathrm{~mm}$ & $0.95 \mathrm{~mm}$ \\
\hline
\end{tabular}

Table 4 Distribution of mean of highest point of humeral head and greater tubercle

\begin{tabular}{|c|c|c|c|c|c|}
\hline \multicolumn{3}{|c|}{ LEFT HHGT } & \multicolumn{3}{c|}{ RIGHT HHGT } \\
\hline Mean & $\begin{array}{c}\text { Std. } \\
\text { Deviation }\end{array}$ & $\begin{array}{c}\text { Std. Error } \\
\text { Mean }\end{array}$ & Mean & $\begin{array}{c}\text { Std. } \\
\text { Deviation }\end{array}$ & $\begin{array}{c}\text { Std. Error } \\
\text { Mean }\end{array}$ \\
\hline $6.26 \mathrm{~mm}$ & $1.25 \mathrm{~mm}$ & $0.32 \mathrm{~mm}$ & $7.24 \mathrm{~mm}$ & $2.09 \mathrm{~mm}$ & $0.54 \mathrm{~mm}$ \\
\hline
\end{tabular}




\section{Discussion}

\section{Hume rus Length (HI)}

In our present study we found mean value of humerus length (MHL) in North Indian population on left side is $290.2 \pm 27.8 \mathrm{~mm}$ and on right side is $291.2 \pm 28.7 \mathrm{~mm}$. while comparing our study with Prasad NC et al ${ }^{[5]}$, Lakshmi et al. ${ }^{6}$, Rahul Rai et $\mathrm{al}^{7}$, and Aydin Kabakci. ${ }^{8}$ et al whose finding value was $302.8 \pm 25.6 \mathrm{~mm}$ on right side and $296.75 \pm 19.6 \mathrm{~mm}$ on left side, $303.91 \pm 19.28 \mathrm{~mm}$ and $306.19 \pm 18.02 \mathrm{~mm}$ on the left and right side respectively, $302.6 \pm 21.4 \mathrm{~mm} \& 297.5 \pm 21.1 \mathrm{~mm}$ on the right and left side respectively.304.1 17 17.3 mmright and $300.4 \pm 23.9 \mathrm{~mm}$ was left and this value was similar with our study.

\section{Transverse Diameter of Humeral Head (TDHH)}

In our current study we found mean values of transverse diameter of humeral head (TDHH) in North Indian population it is $39.53 \pm 4.83 \mathrm{~mm}$ on right side and on the left side it is $36.99 \pm 3.11 \mathrm{~mm}$. while comparing our study with Aydinkabakci et $\mathrm{al}^{8}$ recorded $38.29 \pm 3.04 \mathrm{~mm}$ on right side and on the left side it was $38.66 \pm 3.92 \mathrm{~mm}$ which was similar with our study while comparing with Moumita Chatterjee et $\mathrm{al}^{9}$ there finding was 45.73 on right side and 45.35 left side these value was very high as compare with our value.

\section{Vertical Diameter of Humeral Head (VDHH)}

In our current study we observed that the mean values of vertical diameter of humeral head on the right side is $41.63 \pm 6.01 \mathrm{~mm}$ and on left side $38.89 \pm 3.71 \mathrm{~mm}$. while comparing our study with Aydin Kabakci et $\mathrm{al}^{8}$. There mean values on the right side were $42.41 \pm 3.25 \mathrm{~mm}$ and on the left side were $42.94 \pm 4.0 \mathrm{~mm}$ and these value was almost similar with our finding.

\section{HHGT (Highest Point of Humeral Head and Greater Tubercle)}

In our current study we found HHGT the mean value on the left side is $6.78 \pm 1.40 \mathrm{~mm}$ and on right side $7.36 \pm 1.03 \mathrm{~mm}$. similar study was performed by Moumita Chatterjee et $\mathrm{al}^{8}$, and Ayd in Kabakci et al ${ }^{9}$ there mean value was $6.30 \pm$ $1.1 \mathrm{~mm}$ for the right side and $5.91 \pm 1.14 \mathrm{~mm}$ for the left side, and $6.39 \pm 1.44 \mathrm{~mm}$ on the right side and on the left side is $5.83 \pm 1.72 \mathrm{~mm}$. Which was similar with our study.

\section{Conclusion}

Morphometric study is very helpful in forensic, anatomic and archaeological. These study help in cases in identification of unknown bodies and to determine stature of the individual in our population and as well as for the orthopaedic surgeons for the treatment of proximal humerus fractures and for their reconstruction. These measurements play an important role in prosthesis manufacturing units or authorities, in designing the same on basis of racial and ethnic variations. These data help in further correlation with radiological data and formulate new techniques for effective remodelling of the prosthesis.

\section{References}

1. Gray's Anatomy Edition 40th page 796800.

2. Prashanth K, Pai M, Murlimanju B, Prabhu L, Prameela M. Estimation of the Humerus Length by its Proximal Segments: A South Indian Anatomical Study. J Morphol Sci. 2019;1-4

3. Carofino BC, Leopold SS. Classifications in brief: the Neer classification for proximal humerus fractures. Clin Orthop Relat Res. 2012;471(1):39-43.

4. Illustrated clinical anatomy by peter Abrahams john craven, john lumerley page no 162.

5. Prasad NC, Shivashankarappa A, Pavan P Havaldar, Shruthi BN and Shaik Hussain Saheb A study on segments of humerus and its clinical importance 2017;3(4):7524

6. Lakshmi Kantha. B.M, Roopa Kulkarni . Estimation of total length of humerus from its fragments in South Indian population International Journal of Anatomy and Research, Int J Anat Res 2014;2(1):21320. 
7. Rahul Rai and Maheshwar Chawla Morphometry of adult humerus bone in moradabad region IJBAR 2014;05(3):1-5

8. Aydin Kabakci, A. D.; Buyukmumcu, M.; Yilmaz, M. T.; Cicekcibasi, A. E.; Akın, D. \& Cihan, E. An osteometeric study on humerus bones. Int. J. Morphol. 2017; 35(1):219-26

9. Moumita Chatterjee, Iman Sinha, Ratnadeep Poddar, Asis Kumar Ghosal. Humeral Morphometrics: A Study In Eastern Indian Population International Journal of Anatomy and Research, Int J Anat Res 2017;5(4):4454-69. 